\title{
Orientação Empreendedora, Capacidade de Aprendizagem Organizacional e Desempenho Inovador no Setor Microcervejeiro
}

\author{
Linda Jessica De Montreuil Carmona ${ }^{1}$, Leandro Cerutti Jr. ${ }^{2}$, Giancarlo Gomes ${ }^{3}$, Pedro Lucas \\ Resende Melo ${ }^{4}$ \\ ${ }^{1}$ Fundação Universidade Regional de Blumenau (FURB) - lcarmona@furb.br \\ ${ }^{2}$ Fundação Universidade Regional de Blumenau (FURB) - leandroceruttijr@gmail.com \\ 3 Fundação Universidade Regional de Blumenau (FURB) - giancarlo@pzo.com.br \\ 4 Universidade Paulista (UNIP) - resendemelo@usp.br
}

PALAVRAS-CHAVE

Inovação de produtos;

Orientação Empreendedora;

Capacidade de Aprendizagem;

Organizacional;

Desempenho;

Microcervejarias.

Received 18.05.2018

Accepted 19.06.2018

ISSN 1980-4431

Double blind review

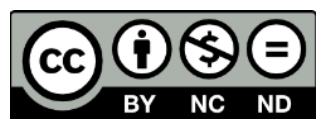

RESUMO

O setor microcervejeiro vem ganhando visibilidade e conquistando o gosto do consumidor brasileiro de cervejas especiais, cujos fabricantes apostam por uma produção artesanal ou semiartesanal, focando na inovação dos produtos, na qualidade das matérias primas e na utilização de regras de produção rígidas. A presente pesquisa qualitativa teve como objetivo analisar a relação entre a orientação empreendedora (OE) e a capacidade de aprendizagem organizacional (CAO) na geração de desempenho inovador (DI) e organizacional (DO) em um conjunto de sete organizações do setor microcervejeiro, sediadas em cinco cidades do Estado de Santa Catarina. Os dados foram coletados mediante entrevistas semiestruturadas, aplicadas a oito gestores e colaboradores da área de produção das microcervejarias, utilizando a técnica de análise de conteúdo. Os resultados apontaram à verificação da relação entre a $\mathrm{OE}$ e a $\mathrm{CAO}$ como antecedentes do processo inovativo e como facilitadores do desempenho inovador e organizacional. Ainda, observou-se que a centralização de autoridade na organização familiar, estrutura típica do setor microcervejeiro catarinense, desacelera a inovação de produtos.

\section{KEYWORDS}

Product Innovation;

Entrepreneurial Orientation;

Organizational Learning;

Capability;

Performance;

Microbreweries.

\section{ABSTRACT}

The microbrewery industry has been gaining visibility and the taste of the Brazilian consumer of special beers, whose manufacturers are betting on artisanal or semiartesanal production, focusing on product innovation, on the quality of raw materials and in the use of rigid production standards. This qualitative research aimed at analyzing the relationship between entrepreneurial orientation (EO) and organizational learning capability (OLC) on the innovation and firm performance of a group of seven microbreweries located on five cities of the State of Santa Catarina, Brazil. Data were collected through semi-structured interviews, applied to eight CEOs and production managers, using the content analysis technique to interpret research findings. Results pointed to the verification of the relationship between EO and OLC as antecedents of the innovative process and as facilitators of innovation and organizational performance. Also, it was observed that centralization of authority in the family firms, the typical organization of the Santa Catarina, slows the product innovation processes. 


\section{Introdução}

A orientação empreendedora $(\mathrm{OE})$ pode ser definida como a capacidade de uma organização de demonstrar proatividade estratégica, envolvendo riscos calculados, o que se reflete nas intenções dos gestores a favor de comportamentos e tarefas empreendedoras, no processo de busca e exploração de novas oportunidades (Covin \& Slevin, 1989; Huang \& Wang, 2011; Hult, Hurley, \& Knight, 2004; Zhao, Li, Lee, \& Chen, 2011). O gestor como empreendedor, é o responsável pelo desenho das mudanças controladas na sua organização (Hult et al., 2004), influindo na escolha do tipo de aprendizagem organizacional a ser adotado (Zhao et al., 2011).

A inovação contínua constitui-se no motor da OE, pois permite estabelecer bases para a consecução de vantagens competitivas futuras (Fernández-Mesa, Alegre-Vidal, \& Chiva-Gómez, 2012; Ireland \& Webb, 2007). A inovação auxilia as organizações a lidarem com ambientes turbulentos, sendo, portanto, um dos direcionadores chave do sucesso em longo prazo (Jiménez-Jiménez \& Sanz-Valle, 2011).

A inovação parece depender da capacidade das organizações para aprender (Alegre \& Chiva, 2008). Alguns estudos sugerem que tanto a aprendizagem organizacional como seu resultado, o conhecimento, são antecedentes da inovação (Baker \& Sinkula, 1999; Jiménez-Jiménez \& SanzValle, 2011), porque permitem às organizações conseguir a velocidade e flexibilidade inerentes ao processo inovativo (Brown \& Eisenhardt, 1995).

Em um sentido geral, a aprendizagem organizacional sugere o desenvolvimento de novo conhecimento, que influi no comportamento dos colaboradores (Slater \& Narver, 1995). Alegre e Chiva (2008) ponderam que a aprendizagem implica uma mudança nos modelos organizacionais para manter ou melhorar o desempenho organizacional. Outros autores distinguem a aprendizagem organizacional como processo útil na geração de novas ideias, que possibilita aos gestores com orientação empreendedora a modelagem de organizações que aprendem (Hurley \& Hult, 1998; Wang, 2008).

As organizações são forçadas a aprender um novo conhecimento para desenvolverem novos produtos e assim satisfazer novos mercados e clientes (Huang \& Wang, 2011). Destarte, o conhecimento se constitui em um recurso estratégico importante para a manutenção da vantagem competitiva, uma vez que ele permite a criação de novo conhecimento, fator crítico no sucesso (Aizpurúa, Saldaña, \& Saldaña, 2011; Ipe, 2003).

De acordo com Atuahene-Gima, Slater e Olson (2005) o desempenho inovador é um importante indicador do resultado da inovação, pois permite mensurar a lucratividade, o volume de vendas e os objetivos de receitas de uma empresa, a partir de produtos e serviços novos (Chen, Wang, Nevo, Benitez-Amado, \& Kou, 2015). A literatura aponta o caráter interativo do processo inovativo, sugerindo que este seja favorecido pela presença de relações, redes, alianças e outras interações com fontes externas de conhecimento, como clientes e fornecedores (Brown \& Eisenhardt, 1995; Ren, Eisingerich, \& Tsai, 2015).

Consoante com os argumentos anteriores, esta pesquisa pretendeu responder à seguinte pergunta: Como a orientação empreendedora e a capacidade de aprendizagem organizacional influenciam o desempenho inovador e organizacional em empresas do setor microcervejeiro catarinense? Assim o objetivo deste trabalho foi compreender a relação da $\mathrm{OE}$ e da CAO na facilitação do desempenho inovador e organizacional, analisando como estes conceitos se associam e desenvolvem.

Quanto ao cenário cervejeiro brasileiro, este se encontra atualmente bipolarizado, tendo de um lado às grandes indústrias, que produzem de forma massificada, com destaque para variedade de cerveja Standard Lager. Por outro lado, testemunha-se o renascimento da indústria cervejeira artesanal (Morado, 2009), pelo qual as microcervejarias artesanais priorizam a fabricação de bebidas de melhor qualidade, tentando quebrar o mainstream (Giorgi \& Conceição Junior, 2016). Prova disto é que o mercado brasileiro de cervejas artesanais cresceu $36 \%$ no consumo de cervejas especiais, fortes e premium, somente no triênio de 2012 à 2014 (Sebrae, 2015).

Desde uma perspectiva histórica, a partir das décadas de 1980 e 1990, enquanto fusões e alianças de grandes grupos cervejeiros aconteciam, surgia na Itália o movimento slow beer, cuja filosofia prega o resgate da história, da cultura e do prazer de beber boas cervejas, associada à gastronomia de qualidade, em sintonia com a proposta do movimento slow food, relacionada à preservação e valorização da culinária regional (Ferreira,

Revista de Negócios, v. 22, n. 3, p. 64-8o, July, 2017. 
Vasconcelos, Martins, \& Neves, 2011), e de lógica contrária à fast food (Ferreira et al., 2011; Morado, 2009).

À "gourmetização" da produção e consumo de cervejas artesanais, somou-se a abertura de modernas microcervejarias e choperias no Brasil, que ampliam as opções de estilos e propõem aos consumidores uma relação diferenciada. As cervejarias artesanais ou "homebrewers" foram dando passo às confrarias, associações e a um importante número de estabelecimentos de cervejas especiais, eventos, cursos de formação de "sommeliers" etc., promovendo a valorização da bebida nos diversos aspectos: histórico, cultural, nutritivo, dentre outros-, distinguindo o produto artesanal do massificado (Giorgi, 2016; Morado, 2009).

A elaboração deste estudo justifica-se pela importância do setor microcervejeiro na economia catarinense. Estima-se que no Brasil existem 500 microcervejarias, $91 \%$ das quais se encontram localizadas nas regiões Sul e Sudeste (Koch, 2017). Santa Catarina conta com mais de 60 marcas e centenas de rótulos, existindo um impacto desta indústria com o setor de gastronomia, turismo e eventos (SEBRAE, 2015). Além disso, são poucos os estudos que fazem uma análise mais detalhada desta indústria artesanal aparecendo apenas breves comentários dentro de estudos da indústria cervejeira como um todo (Cunha, 2011).

\section{Referencial Teórico}

2.1 Orientação Empreendedora, Desempenho Inovador e organizacional

O termo "orientação empreendedora" foi proposto inicialmente por Miller e Friesen em 1983 e embora ele tenha sido definido abrangendo muitas dimensões diferentes, na literatura são identificadas constantemente quatro delas: inovatividade, proatividade e propensão ao risco e agressividade competitiva (Huang \& Wang, 2011; Lumpkin \& Dess, 1996).

Inovatividade caracteriza a uma organização que busca de novas ideias e conceitos no desenvolvimento de processos, produtos ou serviços. "As empresas inovativas são aquelas que exibem um comportamento consistentemente inovador" (Wang, 2008, p. 637). A proatividade descreve à organização que se caracteriza pelo olhar ao futuro e que é responsiva ao seu ambiente setorial. A aceitação de riscos significa que a organização busca oportunidades empreendedoras considerando os recursos que possa, ou não, ter (Huang \& Wang, 2011). Miller e Friesen (1983) caracterizam a agressividade competitiva referindo-se à postura aguerrida diante das disputas competitivas.

As organizações com maior OE são mais propensas a eliminar estruturas tradicionais autoritárias e hierárquicas que inibem a aprendizagem colaborativa, fato que é particularmente válido em empresas de médio e grande porte, onde a flexibilidade garante aos indivíduos a liberdade de exercer a criatividade. Nesse contexto, os colaboradores são motivados e inspirados a aprender, mostrando um maior nível de comprometimento (Wang, 2008).

De acordo com Rauch et al. (2009), a OE influência no processo de formulação estratégica, fornecendo às organizações bases para as ações e decisões empreendedoras. A OE está relacionada com a tomada de decisão estratégica, bem como, com os processos de gestão (Lumpkin \& Dess, 2001). Nesse contexto, a OE aprimora e contribui com a performance organizacional (Alegre \& Chiva, 2013; Ireland \& Webb, 2007; Moreno \& Casillas, 2008; Rauch et al., 2009), sendo considerada determinante para melhoria da inovação de uma organização (Atuahene-Gima \& Ko, 2001). De acordo com Wang (2008), estudos empíricos anteriores demonstram que as organizações com mais OE apresentam melhores resultados.

A literatura de inovação tem-se focado constantemente nas atividades empreendedoras e sua relação com o desempenho inovador, abrangendo a renovação estratégica, o empreendimento e a inovação de produtos (Huang \& Wang, 2011). Estudos realizados nos Estados Unidos apontam a uma relação positiva entre $\mathrm{OE} e$ o DI, no entanto, esta relação nem sempre tem sido confirmada em economias emergentes o que pode ser explicado por diferenças contextuais entre países (Lumpkin \& Dess, 1996; Zhao et al., 2011).

Alguns fatores influenciam no desenvolvimento da OE, tais como: o acesso a capital financeiro, o tamanho da organização e o nível tecnológico (Wang, 2008). O acesso ao capital em geral produz um efeito positivo no resultado, de tal modo que a OE pode ser utilizada como mecanismo para superar eventuais restrições financeiras em ambientes com poucas 
oportunidades (Wiklund \& Shepherd, 2005). Outros estudos apontam a outras relações da OE, que é difundida também pela cultura nacional (Rauch et al., 2009), capacidade de networking e pelos processos estratégicos (Wang, 2008).

Em empresas pequenas e médias, o efeito da OE no crescimento destas é maior, pois a avaliação e exploração de oportunidades de mercado podem ser atribuídas à $\mathrm{OE}$. A habilidade para ter sucesso ao abordar oportunidades de mercado é consequência de atitudes proativas, inovativas e de propensão ao risco, podendo os fundadoresgestores escolher a extensão e velocidade de crescimento (Eggers \& Kraus, 2012).

2.2 Capacidade de Aprendizagem Organizacional, Desempenho Inovador e Organizacional

Conforme Amara, Landry, Becheikh e Ouimet (2008) é fundamental que as pequenas e médias empresas voltem-se ao desenvolvimento e implementação da aprendizagem organizacional, permitindo a disseminação e exploração do conhecimento dentre a organização, bem como, do ambiente externo, podendo refletir, posteriormente, na inovação.

A CAO ou orientação ao aprendizado é um tipo de capacidade baseada no conhecimento que dá suporte à inovação contribuindo com seu sucesso. A CAO envolve componentes-chave que sustentam os processos produtivos baseados em conhecimento, incluindo a busca da informação e o desenvolvimento de novo conhecimento de produtos, processos e serviços (Huang \& Wang, 2011).

De acordo com Forrester (2000), o interesse na aprendizagem organizacional se intensificou durante a década de 1980, quando as organizações viam-se a si próprias como "organizações que aprendem" (Senge, 2009), existindo uma aparente coincidência nos modelos de aprendizagem organizacional e de inovação. Além da perspectiva de aprendizagem individual, a grupal oferecia o potencial benefício sinérgico para resolução coletiva de problemas.

Gradativamente o debate sobre o processo de aprendizagem organizacional intensificou-se, focando-se nas capacidades absortivas das organizações e consequentemente, em seu potencial inovativo (Aragón-Correa, GarcíaMorales, \& Cordón-Pozo, 2007; Hurley \& Hult, 1998; Nonaka \& Takeuchi, 1995; Trigo, 2013). São os mecanismos de aprendizagem organizacional, junto da liderança transformacional, os que fomentam a criatividade dos colaboradores, melhorando o potencial inovador da organização (Gumusluoglu \& Ilsev, 2009; Knudsen \& Cokpekin, 2011).

Jiménez-Jiménez \& Sanz-Valle (2011) apontam uma relação positiva entre a aprendizagem organizacional, a inovação e o desempenho, indicando que os estudos têm demonstrado que os valores culturais promovem e suportam a inovação, principalmente de produto. Hurley e Hult (1998) consideram que maiores níveis de inovatividade estão diretamente correlacionados a uma cultura de negócios baseada na aprendizagem e tomada de decisão participativa.

Alguns estudos qualitativos confirmam que a aprendizagem organizacional melhora a inovação. A pesquisa de Forrester (2000) encontra uma relação positiva entre a $\mathrm{AO}$ e a inovação na comparação do desempenho de duas equipes de inovação, cujo propósito era de reduzir custos. Yeung, Lai e Yee (2007) evidenciaram que a aprendizagem organizacional acontece quando valorizada pela alta administração e apoiada por uma infraestrutura adequada para a aprendizagem e cultura, levando à eficiência organizacional.

Sorensen e Stuart (2000) ponderam que a idade da empresa a fornece de experiência e competências organizacionais permitindo $\mathrm{o}$ desenvolvimento de operações mais refinadas e eficientes, sobretudo aquelas relativas à inovação. Por outro lado, as rotinas organizacionais imaturas de empresas jovens se constituem em obstáculo no desenvolvimento da inovação.

Outros fatores que moderam a relação da CAO com o desempenho inovador são o tamanho, setor industrial e turbulência do mercado, principalmente em empresas pequenas, mais antigas, operando em ambientes turbulentos, sendo esta relação mais intensa no setor serviços (Jiménez-Jiménez \& Sanz-Valle, 2011). A literatura também conecta a capacidade de aprendizagem à renovação da organização (Crossan \& Berdrow, 2003).

Para Alegre e Chiva (2008) a CAO pode ser representada mediante cinco dimensões ou mecanismos: experimentação, propensão ao risco, interação com o ambiente externo, diálogo e tomada de decisão participativa. A experimentação pode ser definida como o grau em que novas ideias e sugestões são atendidas e encorajadas, o que

Revista de Negócios, v. 22, n. 3, p. 64-8o, July, 2017. 
envolve a procura de soluções inovadoras, possibilitando soluções de problemas com base na utilização de novos métodos e procedimentos. Nesta dimensão também são incluídos o treinamento continuo e a vontade dos colaboradores de aprender e se superar.

A propensão ao risco caracteriza-se pela tolerância à ambiguidade, incerteza e erros. Organizações que encaram erros como inaceitáveis não são promotoras do aprendizado. Bapuji e Crossan (2004) definem a interação com o ambiente externo como a intensidade das relações que uma organização mantém com o ambiente imediato. O diálogo é definido como uma busca coletiva recorrente de processos, pressupostos e certezas que compõem a experiência cotidiana (Alegre \& Chiva, 2008; Chiva \& Alegre, 2009; Isaacs, 1993).

A tomada de decisão participativa refere-se ao nível de influência que os funcionários têm no processo de decisão. Ao ser implementada a participação, as organizações podem se beneficiar dos efeitos de um maior envolvimento, satisfação e compromisso dos colaboradores (Scott-Ladd \& Chan, 2004). A literatura considera a tomada de decisão participativa como um dos aspectos que facilitam o aprendizado (Alegre \& Chiva, 2008).

\subsection{Capacidade de Aprendizagem Organizacional e} Orientação Empreendedora

Organizações com maiores níveis de $\mathrm{OE}$ consideram o conhecimento e a aprendizagem como meio para desenvolver vantagens competitivas (Zhao et al., 2011) e requerem de pessoas competentes para aprender e interpretar nova informação de mercado e mudanças tecnológicas provindas do ambiente externo. Neste sentido, os colaboradores precisam processar a informação de maneira eficiente e com maior velocidade que os seus concorrentes (Huang \& Wang, 2011).

Hult, Ketchen e Arrfelt (2007) argumentam a favor da OE como um fator da cultura de competitividade das organizações, que age sinergicamente com o desenvolvimento do conhecimento na melhoria do desempenho organizacional. No estudo do efeito da inovação no desempenho organizacional, Hult et al. (2004) identificaram que a $\mathrm{OE}$ e a aprendizagem organizacional são antecedentes da inovação. Para Wang (2008), a CAO media a relação entre a OE e o desempenho organizacional. Sobre este ponto Bapuji e Crossan (2004) indicam que a CAO não só impacta a performance organizacional, mas também atua como moderadora ao melhorar variáveis de desempenho individual.

Fernández-Mesa et al. (2012) sugerem que certos fatores organizacionais facilitam o processo de aprendizagem e influenciam a relação entre a OE e o desempenho inovador ao estarem ambas variáveis mediadas pela CAO. Portanto, a OE deve ser reforçada para facilitar a aprendizagem e melhorar tanto a performance inovadora como organizacional.

Figura 1. Modelo Conceitual da relação da OE-CAO com o desempenho inovador e organizacional

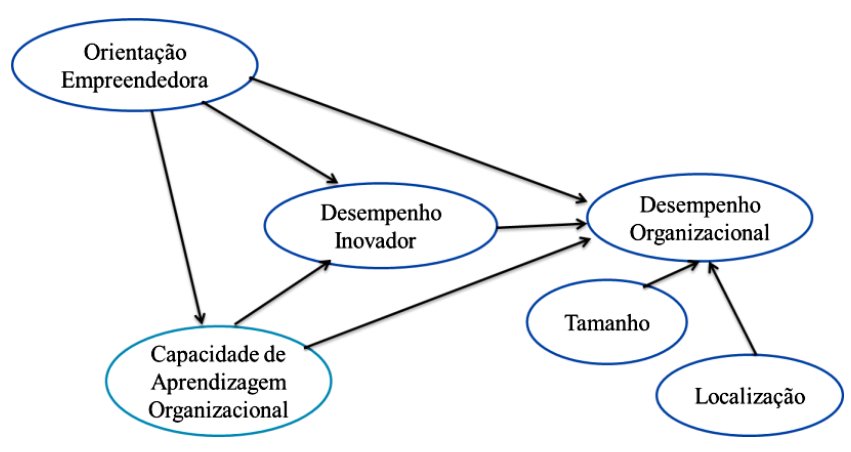

Fonte: Alegre e Chiva (2013).

$\mathrm{Na}$ figura supracitada, Alegre e Chiva (2013) propõem que a OE e a CAO influem no desempenho inovador e organizacional e que esta relação pode ser moderada pelo tamanho e localização da firma.

\section{Metodologia}

A pesquisa, quanto ao seu objetivo foi caracterizada como descritiva de abordagem qualitativa, com uso de dados primários provindos de entrevistas semiestruturadas realizadas em empresas do setor microcervejeiro catarinense e dados documentais facilitados pelas mesmas.

\subsection{Sujeitos de Pesquisa}

O processo de escolha dos sujeitos na pesquisa qualitativa difere da amostragem na pesquisa quantitativa, no sentido de que o objetivo é distinto e focado na compreensão do fenômeno (Bauer \& Gaskell, 2002; Maykut \& Morehouse, 1994), sendo o número apropriado de sujeitos, aquele que responde adequadamente à pergunta de

Revista de Negócios, v. 22, n. 3, p. 64-8o, July, 2017. 
pesquisa (Marshall, 1996). Neste trabalho, os sujeitos de estudo são altos gestores e colaboradores da equipe de produção de microcervejarias, cujo perfil é apresentado na Tabela 1.

Tabela 1. Perfil dos Sujeitos da Pesquisa

\begin{tabular}{|c|c|c|c|c|c|c|}
\hline No. & Educação & $\begin{array}{l}\text { Exp. } \\
\text { (anos) }\end{array}$ & Cargo & Empresa & Cidade & Exp \\
\hline 1 & $\begin{array}{l}\text { Ensino } \\
\text { médio }\end{array}$ & 6 & $\begin{array}{c}\text { Auxiliar } \\
\text { Produção }\end{array}$ & Oktobier & Blumenau & 6 \\
\hline 2 & $\begin{array}{c}\text { Superior } \\
\text { Gastronomia/ } \\
\text { téc. Cerveja }\end{array}$ & 7 & $\begin{array}{l}\text { Técnico } \\
\text { Cervejeiro }\end{array}$ & Oktobier & Blumenau & 4 \\
\hline 3 & $\begin{array}{l}\text { Superior / } \\
\text { Pós-grad. }\end{array}$ & 19 & $\begin{array}{l}\text { Sócio } \\
\text { gestor }\end{array}$ & Container* & Blumenau & 3 \\
\hline 4 & $\begin{array}{l}\text { Superior / } \\
\text { Pós-grad. }\end{array}$ & 12 & Gestor & $\begin{array}{c}\text { Cervejaria } \\
\text { Artesanal }\end{array}$ & $\begin{array}{c}\text { Jaraguá } \\
\text { do Sul }\end{array}$ & 12 \\
\hline 5 & $\begin{array}{l}\text { Superior / } \\
\text { Pós-grad. }\end{array}$ & 8 & Gestor & $\begin{array}{l}\text { Escola Sup. } \\
\text { da Cerveja } \\
\text { e Malte* }\end{array}$ & Blumenau & 3 \\
\hline 6 & $\begin{array}{l}\text { Superior / } \\
\text { Pós-grad.. }\end{array}$ & 17 & $\begin{array}{c}\text { Diretor } \\
\text { Comercial }\end{array}$ & Zehnbier* & Brusque & 2 \\
\hline 7 & $\begin{array}{l}\text { Superior / } \\
\text { Pós-grad. }\end{array}$ & 16 & $\begin{array}{c}\text { Gerente } \\
\text { de } \\
\text { Produção }\end{array}$ & Das Bier* & Gaspar & $61 / 2$ \\
\hline 8 & $\begin{array}{c}\text { Superior } \\
\text { Economia }\end{array}$ & 20 & $\begin{array}{c}\text { Gerente } \\
\text { Geral }\end{array}$ & Wunderbier & Blumenau & 10 \\
\hline
\end{tabular}

Fonte: Dados da Pesquisa (2017).

*Projeto Turístico Regional Vale da Cerveja/SC.

A seleção dos sujeitos deu-se de modo intencional, por homogeneidade, que significa a escolha de participantes que experimentam o fenômeno central ou conceito-chave, sendo estes sujeitos membros de um subgrupo com características distintas (Creswell, 2010). Nesta pesquisa, os oito gestores entrevistados atuam em diversas microcervejarias, que são integrantes da Associação das Microcervejarias Artesanais de SC (ACASC), sendo algumas destas participantes do Projeto turístico regional denominado o Vale da Cerveja/SC.

\subsection{Coleta de Dados}

Aarts e Bauer (2002, p. 44) utilizam a definição de Corpus de pesquisa criada por Barthes em 1967, descrevendo-o como "uma coleção finita de materiais, determinada de antemão pelo analista com (inevitável) arbitrariedade, e com a qual ele irá trabalhar". Assim, o corpus desta pesquisa proveio de oito entrevistas semiestruturadas realizadas com responsáveis pela gestão e produção das microcervejarias, coletadas em visitas às unidades fabris, localizadas nas cidades de Blumenau, Timbó, Gaspar, Jaraguá do Sul e Brusque/SC, durante o período de 21 de Junho de 2016 a 01 de Fevereiro de 2017.

Dentre os documentos proporcionados pelos entrevistados pode-se mencionar: o perfil institucional, portfólio de produtos, relatórios de lançamento de novos produtos, listagem de eventos, que serviram para triangulação de dados (Chiva, Ghauri, \& Alegre, 2014). A composição do Corpus é apresentada na Tabela 2.

Tabela 2. Composição do Corpus da Pesquisa

\begin{tabular}{|c|c|c|c|c|}
\hline No. & Empresa & $\begin{array}{c}\text { Tipo de } \\
\text { Entrevista }\end{array}$ & $\begin{array}{c}\text { Data da } \\
\text { Entrevista }\end{array}$ & Duração \\
\hline 1 & Oktobier & \multirow{8}{*}{ 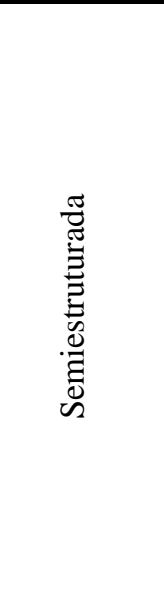 } & $01 / 11 / 2016$ & $35^{\prime} 14^{\prime \prime}$ \\
\hline 2 & Oktobier & & 26/01/2017 & 41'10', \\
\hline 3 & Container & & 25/01/2017 & $47^{\prime} 18^{\prime \prime}$ \\
\hline 4 & $\begin{array}{c}\text { Cervejaria } \\
\text { Artesanal }\end{array}$ & & 09/06/2016 & $57^{\prime} 51^{\prime \prime}$ \\
\hline 5 & $\begin{array}{l}\text { Escola } \\
\text { Sup.da } \\
\text { Cerveja }\end{array}$ & & $21 / 06 / 2016$ & $29^{\prime} 46^{\prime \prime}$ \\
\hline 6 & Zehnbier & & 01/02/2017 & $48^{\prime} 23^{\prime \prime}$ \\
\hline 7 & Das Bier & & 03/11/2016 & $59 ’ 24^{\prime \prime}$ \\
\hline 8 & Wunderbier & & 03/02/2017 & 80’20”' \\
\hline
\end{tabular}

Tempo Total: $\quad 6$ horas, 39 minutos e 26 segundos

Fonte: Dados da Pesquisa (2017).

\subsection{Análise de dados}

A técnica utilizada foi a de análise de conteúdo. De acordo com Flick (2009, p. 292), este tipo de análise inclui basicamente três processos: a síntese de análise de conteúdo, a análise explicativa de conteúdo e a análise estruturadora de conteúdo. Na primeira, abreviação da análise de conteúdo, o material é parafraseado. Os trechos ou paráfrases menos relevantes são omitidos (primeira redução), os semelhantes são condensados e resumidos (segunda redução). A análise explicativa do conteúdo esclarece trechos difusos, ambíguos ou contraditórios, envolvendo material de contexto na análise. A análise estruturadora busca tipos ou estruturas formais no material.

Durante a análise de dados, diversas categorias e subcategorias foram classificadas e categorizadas e realizada a codificação, cobrindo todas as unidades temáticas identificadas nas

Revista de Negócios, v. 22, n. 3, p. 64-8o, July, 2017. 
entrevistas (Eggers \& Kraus, 2012), processo que foi realizado com ajuda do software de pesquisa qualitativa QSR NVivo v.11® para análise de conteúdo dos dados coletados e enumerados na tabela 2.

Para esse estudo, foram selecionadas categorias elencadas na literatura, que apontam a relação entre a $\mathrm{OE}$ e a CAO na facilitação do desempenho inovador e organizacional. Também, foram incluídos outros tópicos de inovação, conforme Tabela 3.

Tabela 3. Síntese das Categorias da Pesquisa.

\begin{tabular}{|c|c|c|}
\hline $\begin{array}{l}\text { Orientação } \\
\text { Empreendedora } \\
\text { Wang (2008) }\end{array}$ & $\begin{array}{l}\text { Capacidade de } \\
\text { Aprendizagem } \\
\text { Organizacional } \\
\text { Alegre \& Chiva } \\
(2008)\end{array}$ & $\begin{array}{l}\begin{array}{l}\text { Inovação e } \\
\text { Desempenho } \\
\text { Inovador }\end{array} \\
\text { Atuahene-Gima et al. } \\
\text { (2005); Brown \& } \\
\text { Eisenhardt (1995); Ren } \\
\text { et al. (2015) }\end{array}$ \\
\hline $\begin{array}{l}\text { Proatividade no } \\
\text { Mercado } \\
\text { Agressividade } \\
\text { competitiva } \\
\text { Aceitação de } \\
\text { Risco } \\
\text { Inovatividade da } \\
\text { Empresa }\end{array}$ & $\begin{array}{l}\text { Experimentação } \\
\text { Propensão ao } \\
\text { Risco } \\
\text { Interação com o } \\
\text { Ambiente } \\
\text { Externo } \\
\text { Diálogo Interno } \\
\text { Tomada de } \\
\text { Decisão } \\
\text { Participativa }\end{array}$ & $\begin{array}{l}\text { Geração dos novos } \\
\text { produtos. } \\
\text { Novos projetos de } \\
\text { inovação. } \\
\text { Avaliação do } \\
\text { desempenho inovador. } \\
\text { Inovação colaborativa. } \\
\text { Relação da OE-CAO } \\
\text { no DI. }\end{array}$ \\
\hline
\end{tabular}

Fonte: Elaborado pelos autores (2017)

\section{Análise e Discussão}

A seguir, uma breve descrição das unidades temáticas identificadas nos textos. Estas foram agrupadas em três categorias: orientação empreendedora, capacidade de aprendizagem organizacional e inovação e desempenho inovador, evidenciadas no corpus desta pesquisa. A discussão teórica dos resultados é apresentada no tópico 4.5 .

\subsection{Orientação Empreendedora}

\subsubsection{Proatividade no mercado}

Diversas microcervejarias começaram como hobby familiar ou de grupo de amigos, para logo identificar a oportunidade de negócio. Sendo a região de colonização alemã, era este o modelo que prevalecia, no qual cada cidade tem sua própria cervejaria. Posteriormente a iniciativa bem- sucedida da Eisenbahn (hoje do grupo Brasil Kirin), centrada na variedade de sabores, qualidade do produto e posicionamento da marca, fez com que outros seguissem o mesmo caminho, com propostas diversas. Segue o depoimento do entrevistado número 4.

O que eu noto como característica fundamental é que grande parte começou como hobby, com membros das famílias, que eram profissionais estabelecidos em outros campos e logo viram uma oportunidade de negócio, seguindo o modelo americano que a Eisenbahn trouxe, fugindo do modelo alemão no qual cada cidade tem sua própria cervejaria (Entrevista Sujeito 4).

Sendo aficionado à cerveja nosso grupo resolveu investir em uma proposta diferenciada. Em uma região dedicada à fabricação de cervejas de estilo alemão decidimos pelo estilo inglês. Nós fomos à Inglaterra buscar tanto o processo produtivo, cervejas diferentes, quanto à cultura (Entrevista Sujeito 3).

\subsubsection{Agressividade Competitiva}

O mercado é percebido pelos microcervejeiros como extremamente agressivo, particularmente na concorrência com as grandes cervejarias. Eles se percebem "amadores" em termos de conhecimento de mercado e distribuição, se sentindo vulneráveis na luta pelos pontos de venda. Empresas maiores utilizam estratégias de preço e contratos de exclusividade para inibir o crescimento das cervejarias artesanais, sabendo que elas não têm escala de produção necessária para ter uma estrutura de custos/preços enxuta. A relação com outras microcervejarias é mais de cooperação do que de concorrência.

O mercado de cerveja é extremamente agressivo. A gente não tinha a mínima ideia de como funcionava o mercado. Da porta para fora da fábrica é outra história. Produzir cerveja a gente domina bem, mas a experiência de colocar o produto no mercado é uma coisa muito difícil. Por exemplo, hoje temos uma cervejaria tradicional no mercado que nos incomoda muito. Ao ponto de nos tirar de pontos comerciais e de fazerem negociações exclusivas para nos inibir, para que você não nasça e não cresça (Entrevista Sujeito 3).

Eu não vejo às pequenas cervejarias como meus concorrentes. O mercado é muito grande, há muito campo para crescer. Eu concorro

Revista de Negócios, v. 22, n. 3, p. 64-8o, July, 2017. 
com empresas que oferecem o produto a um real (Entrevista Sujeito 7).

\subsubsection{Aceitação de Risco}

Os entrevistados se percebem como moderadamente ousados na busca de oportunidades empreendedoras, aproveitando as oportunidades que se apresentam, mas contando com a assessoria técnica necessária e com metas ambiciosas em longo prazo.

Não nos consideramos ousados, mas não
somos tímidos. Em dois anos aumentamos a
produção mensal de seis mil litros para
sessenta mil litros por mês, tínhamos três
pontos de venda, e agora cento e sessenta e
seis, nós estamos em todas as redes de
autosserviço, estamos no Paraná, São Paulo,
Rio de Janeiro, Rio Grande do Sul e Pará.
Somos uma cervejaria nacional, não nos
designaria como agressivos, mas tão pouco
como passivos. Agimos de maneira
profissional, mas com pé no chão (Entrevista
Sujeito 6).

\subsubsection{Inovatividade da Empresa}

Os entrevistados compreendem que a inovatividade é o direcionador do sucesso em longo-prazo. Os novos produtos são orientados pelo mercado. No entanto, limitações tecnológicas, em razão a poucas oportunidades de acesso a capital, inibem a inovatividade.

A inovação tem que ser estar presente no coração da empresa. Se não lançarmos coisas novas todos os anos, acabamos perdendo mercado. Temos vários produtos que vendem bem, mas precisamos mudar a grade constantemente para estarmos sempre chamando a atenção do cliente. Nossos clientes procuram sempre experimentar algo novo (Entrevista Sujeito 7).

Falando por mim, venho de um mercado em que ou se inova ou morre. Nós trouxemos muita inovação para a cervejaria, já mudamos de rótulo e embalagem, desenvolvemos novas marcas, entramos no mercado de "private label”. Em várias situações inovamos de forma agressiva (Entrevista Sujeito 6).

\subsection{Capacidade de Aprendizagem Organizacional}

\subsubsection{Experimentação}

A criação e experimentação são permanentes. Em posse das receitas base, os ajustes são feitos com base no feedback do público. O processo de criação de produtos novos é orientado pelo mercado e apoiado pelas entidades de ensino. O tamanho pequeno da organização permite maior experimentação.

A aprendizagem acontecia com a simulação de fórmulas usando um programa de computador. Registravam-se as fórmulas no computador, $e$ ia se testando, e as particularidades iam se anotando, registrando as vencedoras. $E$ o capital intelectual da organização. Registramse as tentativas, os acertos e erros. Na criação de novas fórmulas se consulta esses registros. Pelos cursos se aprende muita coisa, do que pode ou não ser feito. Mas muito se aprende na prática, guardando os ajustes finos (Entrevista Sujeito 4).

Toda cervejaria precisa ter muita experimentação o tempo todo. Isso porque a qualidade e avaliação do produto se dão muito pelo lado sensorial e degustativo. Sempre que o mestre está aqui, ele passa tanque a tanque, avalia e experimenta. (Entrevista Sujeito 6).

\subsubsection{Propensão ao risco}

Os empreendedores afirmam terem aprendido por experiência, reconhecendo que não tinham muito conhecimento quando começaram. Contudo, entendem que são os gestores que tomam riscos e não os colaboradores, sem preocupar-se por criar o ambiente com abertura para tolerância de erros no nível operativo.

Corremos riscos sim. Na medida em que produzimos algo novo e não sabemos se vai ter demanda para ele. Podemos entender que é um produto excelente, mas podemos produzir mil litros e vender apenas cem. Como nossa produção é empurrada, principalmente no lançamento de novos produtos, é sempre um risco (Entrevista Sujeito 7).

Nossa equipe, como um todo, não assume riscos. Gostaríamos que os colaboradores assumissem risco e trouxessem mais novidade para nós (Entrevista Sujeito 6).

\subsubsection{Interação com o ambiente externo}

Os microcervejeiros interagem com seus pares e com especialistas sommeliers de cerveja, que são donos de cervejarias, para criação de produtos e para compra de matéria prima. Também

Revista de Negócios, v. 22, n. 3, p. 64-8o, July, 2017. 
utilizam o laboratório da Escola da Cerveja para fazerem testes. Esta entidade educativa encabeça o Roteiro Turístico o Vale da Cerveja além de fornecer trainees aos microcervejeiros para fazer estágios profissionais.

Essa parte do processo sempre tem algo a melhorar, quando visitamos outras cervejarias sempre aparecem novas opções, ideias de melhorias. Mas cada cervejaria tem um "DNA" diferente (Entrevista Sujeito 3).

Há um grande espírito de cooperação entre as cervejarias, inclusive emprestando materiais umas às outras. Cervejeiros estão sempre em contato. Então se temos algum problema, entramos em contato e nos ajudamos sempre que possível. Participamos das feiras sempre que possível (Entrevista Sujeito 2).

Não somos uma cooperativa, mas, por exemplo, na hora da compra fazemos negociação com fornecedores para comprar em bloco determinados produtos. Em conjunto podem negociar melhores preços e condições (Entrevista Sujeito 7).

\subsubsection{Diálogo interno}

$\mathrm{Na}$ maioria de casos, por serem empresas pequenas, a comunicação em nível de produção é direta e diária, informal e horizontal. No entanto, por ser empresas de estrutura familiar, a figura do fundador ou patriarca quebra as hierarquias de comunicação, causando desconcerto e incomodo.

A comunicação é direta, por ser uma empresa pequena. A comunicação com os funcionários é diária. Também não tem muita formalidade no contado entre mim e os funcionários. $E$ mudou muito a questão hierárquica no trabalho em geral, você não pode impor as coisas, está negociando o tempo inteiro (Entrevista Sujeito 3).

A empresa têm três níveis: produção (chão de fábrica), gerencial e Conselho. A comunicação é meio truncada, às vezes os problemas vêm da produção diretamente para o Conselho. É isso acaba atrapalhando às vezes. Como a empresa é familiar, o pai às vezes aparece $e$ o encarregado da produção pede: precisamos comprar um tanque. E quem precisa fazer essa decisão é o gerente de produção. Existe uma hierarquia na tomada de decisão. As visões de fábrica, gestão e comercial são diferentes. A comunicação não se dá tão bem quanto deveria (Entrevista Sujeito 7).

\subsubsection{Tomada de Decisão Participativa}

Ela acontece principalmente na parte produtiva, na comercial e estratégica é limitada aos gestores. O tipo de empresa familiar limita a velocidade da tomada de decisão.

No que tange a decisões de produto (cerveja) fica a cargo do mestre cervejeiro, desde que não haja divergência, nesse caso, a decisão fica com a diretoria geral. Decidimos fazer a mudança na gestão, devido à alta carga de trabalho e responsabilidade que eu tinha. Então sentamos eu e meu sócio e dividimos a responsabilidades em comum acordo (Entrevista Sujeito 6).

Somos lentos em tomar decisões. Demoramos mais do que deveríamos para reagir às circunstâncias de mercado. Por ser uma empresa familiar, algumas decisões demoram a ser tomadas, todo mundo fica meio inseguro em tomar uma decisão um pouco mais difícil, acaba demorando um pouco mais do que deveria, o que acaba atrapalhando alguns negócios (Entrevista Sujeito 7).

\subsection{Inovação e Desempenho Inovador}

\subsubsection{Avaliação do Desempenho Inovador}

Os entrevistados têm clara a necessidade de gerar lucros para sobrevivência e de controlar os custos em nível geral, mas não discriminam os relativos aos produtos novos, o que poderia dar uma noção mais clara do resultado da inovação. Isto, em razão à novidade dos empreendimentos ou pela falta de visão estratégica. A avaliação do DI centra-se no monitoramento do lançamento de produtos novos, pontos de venda novos e redução de custos com miras a aumentar a eficiência e diminuir o desperdiço.

A inovação precisa de um controle maior $e$ reduzindo custos que é um fator para melhorar a competitividade. Interessa-nos desperdiçar menos cerveja, fazer cerveja mais rapidamente e com melhor aproveitamento, isso acaba impactando na qualidade da cerveja (Entrevista Sujeito 3).

Quanto ao desempenho, toda cervejaria profissional visa dar lucro, até por sustentabilidade econômica. Controlar os custos na ponta do lápis, matéria prima, funcionários, energia, etc. (Entrevista Sujeito $4)$.

Revista de Negócios, v. 22, n. 3, p. 64-8o, July, 2017. 
Todos os nossos dados e informações ainda são muito recentes, ainda não temos como mensurar o que dá certo. Fazemos o controle de quanto determinada cerveja vende e onde. Mas ainda é prematuro para dizer o que deu certo ou não (Entrevista Sujeito 3).

\subsubsection{Geração dos novos produtos}

Eles nascem com base no mercado, na análise da demanda do que as pessoas estão pedindo, em contraste com as possibilidades de produção, portanto é um processo reativo. Existem tendências que são aproveitadas na definição dos estilos dos novos produtos. Muitos produtores têm um produto "carro-chefe", que produzem todo o ano, além de cervejas sazonais que vão variando com as tendências. Eventos e ocasiões direcionam a criação de produtos novos. Eventualmente, os fabricantes lançam cervejas novas tentando conquistar o público não especializado, que gosta de experimentar novidades.

Buscamos primeiramente no mercado, o que as pessoas estão pedindo. $E$ dentro dessa demanda bolamos o nosso produto. Essa elaboração de produto novo é cara, que implica em um novo rótulo, um registro de produto novo. Então cada rótulo precisa ser muito bem pensado, porque imprime a identidade da empresa. E têm tipos de cerveja que não vendem tanto quanto outros. Observamos este movimento e tentamos ir para onde o mercado está pedindo. É reativo (Entrevista Sujeito 3).

Observamos as tendências, mas estamos sempre provocando o público a experimentar alguma coisa nova. Como é um mercado que está começando a crescer, tem muita coisa que o consumidor não conhece ainda, então vale a pena, de vez em quando, você lançar uma novidade que ninguém lançou, ninguém tem. $O$ público vai buscar, nem que seja só para experimentar (Entrevista Sujeito 7).

\subsubsection{Novos projetos de inovação}

Focam-se mais em processos, visando cortar custos, aumentar a velocidade de produção e aumentar o aproveitamento com menor desperdiço. Ao trabalhar na melhoria dos processos obtêm-se também melhorias na qualidade da cerveja.

Os projetos novos estão se focando no processo em geral, visando desperdiçar menos cerveja. Quanto maior o seu portfólio de produto, mas dificuldade você tem na produção. Hoje a gente trabalha com cinco tipos de cerveja e temos mais duas para serem lançadas, que é um portfólio razoável (Entrevista Sujeito 3).

\subsubsection{Inovação colaborativa}

A colaboração entre microcervejarias com fins de criação de produtos e compras reforça a parceria e concorrência pacífica entre estes. A comunicação dá-se por meio das redes sociais, foros e grupos de discussão e durante eventos da classe. Como fator de diferenciação tem microcervejarias fazendo parcerias internacionais, promovendo a troca de ingredientes nativos de cada país. Existe colaboração com fornecedores e parceiros de educação. As associações de classe promovem a troca para fortalecimento do setor.

Temos uma cerveja colaborativa com uma cervejaria britânica. Misturando ingredientes ingleses e brasileiros. Malte, lúpulo, fermento todos são ingleses e nós adicionamos: goiaba e o açaí e era para ser apenas uma cerveja sazonal. Mas ela teve uma grande aceitação, tanto aqui quanto lá. E ficou na linha de produção. Aqui chamamos ela de Wembley e lá na Inglaterra se chama Maracanã, um trocadilho entre os estádios, o rótulo ficou muito bonito (Entrevista Sujeito 3).

As fórmulas, hoje tem bastante disponibilidade na internet, tem alguns livros que pode comprar, de receitas. Enquanto vai fazendo os cursos, o curso te dá o material. A gente troca informações entre cervejeiros, pelas redes sociais. Como é feita, ingredientes, qual a fervura, a brasagem, a rampagem (Entrevista Sujeito 4).

Até temos o projeto de lançar uma cerveja artesanal característica de Santa Catarina, uma cerveja Sour, com uma acidez um pouco maior, para que seja o estilo catarinense de cerveja (Entrevista Sujeito 7).

\subsubsection{Relação da OE e a CAO no DI}

A influência da OE e da CAO na inovação é percebida pelos microcervejeiros, pela integração das áreas. A OE afeta a postura estratégica de fazer negócios e a CAO na forma como flui a aprendizagem organizacional, que acontece desde a simulação de fórmulas, na experimentação: tentativa, acerto e erro.

A aprendizagem é vista como indispensável para a abordagem da inovação, ao assumir o risco

Revista de Negócios, v. 22, n. 3, p. 64-8o, July, 2017. 
da organização sair da zona de conforto para criar produtos novos, pedidos pelo mercado. A AO ocorre também na evolução do negócio, que visando mudanças estratégicas precisa de novos processos, qualidade, segurança.

A OE influência na inovação por meio da visão estratégica dos gestores. Neste tipo de organizações, as equipes pequenas precisam ser multifuncionais para poder abordar a variedade e velocidade da geração de novos projetos.

Procuramos inovar sempre, e buscar sempre novas técnicas na gestão da produção. Começamos produzindo dois estilos, hoje produzimos dez o que exigiu muita aprendizagem. Estamos implementando um sistema de pasteurização que cria mais uma bifurcação de tipo de produto final. Tudo isso leva a mudanças de estratégias, de pessoal, de ideias e processos (Entrevista Sujeito 7).

Esse aprendizado nos colocou mais próximos do mercado, o que possibilitou melhorar a gestão comercial. E no momento que você se aproxima do mercado, automaticamente está mais aberto à inovação, porque o mercado te impulsiona. Então acho que essa é a grande influência. A inovação ajuda para que a empresa se mantenha. Mas tendo em vista as estratégias propostas pelos sócios (Entrevista Sujeito 6).

\subsection{Temas Emergentes}

\subsubsection{Obstáculos para Inovação}

Alguns tópicos novos surgiram no decorrer das entrevistas. A seguir um resumo destes, com as citações exemplificadoras, conforme apresentado em Tabela 4:

Tabela 4. Principais obstáculos para a inovação no setor Microcervejeiro Catarinense

\begin{tabular}{|c|c|}
\hline Fator & Citação Exemplificadora \\
\hline $\begin{array}{l}\text { Carga Tributária. Na } \\
\text { perspectiva dos } \\
\text { microcervejeiros, o } \\
\text { principal obstáculo é o } \\
\text { Estado, pela carga } \\
\text { tributária e os trâmites } \\
\text { burocráticos. }\end{array}$ & $\begin{array}{l}\text { O maior obstáculo é o sistema } \\
\text { tributário no nosso país. } \\
\text { Poderíamos estar produzindo } \\
\text { muito mais e ter muitos mais } \\
\text { rótulos de cerveja, mas não se } \\
\text { justifica, porque meu produto } \\
\text { final chega muito caro na } \\
\text { gondola devido à tributação. } \\
\text { Também, os processos de } \\
\text { registro são burocráticos e } \\
\text { longos (Entrevista Sujeito 6). }\end{array}$ \\
\hline $\begin{array}{l}\text { Importação } \\
\text { Produtos }\end{array}$ & $\begin{array}{l}\text { Dificuldades maiores são ' } N \text { ' } \\
\text { dificuldades, ainda mais quando }\end{array}$ \\
\hline
\end{tabular}

\begin{tabular}{|c|c|}
\hline $\begin{array}{l}\text { A logística é também } \\
\text { vista como } \\
\text { complicada, pois } \\
\text { grande parte dos } \\
\text { produtos é importada. } \\
\text { Como são produtos de } \\
\text { manuseio delicado, } \\
\text { qualquer variação } \\
\text { climática pode colocar } \\
\text { em risco a produção. }\end{array}$ & $\begin{array}{l}\text { você tem quatro ou cinco } \\
\text { insumos básicos, é dependente } \\
\text { do mercado externo e da } \\
\text { cotação do dólar do dia. Eu não } \\
\text { compro nada que não seja dólar } \\
\text { do dia. E além de tudo são } \\
\text { produtos muito sensíveis, que } \\
\text { qualquer variação influi na } \\
\text { produção, como da cevada, do } \\
\text { próprio [... então é um mercado } \\
\text { tanto quanto delicado } \\
\text { (Entrevista Sujeito 8). }\end{array}$ \\
\hline $\begin{array}{l}\text { Escassez de mão de } \\
\text { obra qualificada. }\end{array}$ & $\begin{array}{l}\text { A mão de obra ainda é escassa, } \\
\text { a pesar dos profissionais } \\
\text { formados pela Escola. O foco da } \\
\text { Escola é formar profissionais } \\
\text { para pequenas cervejarias } \\
\text { (Entrevista Sujeito 7). }\end{array}$ \\
\hline $\begin{array}{lr}\text { Escassez de } & \text { capital. } \\
\text { Necessidade } & \text { de } \\
\text { investimento } & \text { em } \\
\text { infraestrutura } & \\
\text { tecnológica, mesma } \\
\text { que se faz inviável } \\
\text { pela escassez de } \\
\text { capital. }\end{array}$ & $\begin{array}{l}\text { O principal obstáculo para a } \\
\text { inovação é a falta de capital. O } \\
\text { ideal seria fazer um ciclo para a } \\
\text { inovação, porque isso é muito } \\
\text { custoso. A parte mercadológica } \\
\text { não é tão problemática. Mas, o } \\
\text { produto é complicado } \\
\text { (Entrevista Sujeito 8). }\end{array}$ \\
\hline
\end{tabular}

Fonte: Dados da Pesquisa (2017).

\subsubsection{A figura do fundador}

É altamente relevante, porque é quem começou com a ideia o patriarca do clã e mentor. Todas microcervejarias analisadas são empresas familiares.

\begin{abstract}
A figura do fundador é altamente relevante, é tudo. A pessoa que vai lá tem a ideia e começa se alimentar dessas ideias, buscar subsídios em todos os cantos e no nosso caso, são as pessoas que tiveram o capital para aportar, que ainda estamos colocando dinheiro próprio. Mas, a cara da empresa, a alma da empresa como se diz é a dos donos (Entrevista Sujeito 3).
\end{abstract}

\subsubsection{A questão cultural local}

O empreendedorismo, traço típico da cultura germânica, preponderante na região, é identificado pelos microcervejeiros como propulsor da ebulição de iniciativas de cervejarias artesanais.

Mas, cervejaria artesanal existe há mais de
150 anos, desde que vieram os primeiros
imigrantes e colonizadores alemães na região
de Blumenau, Jaraguá, Joinville, etc. Muita
gente fabricava com receitas dos "avós",
"bisavós", receitas artesanais, fazia umas 
"panelinhas", uma junção de uma característica empreendedora, que resgata algo que era feito pela família há muito tempo, $e$ é tradicional da cultura alemã (Entrevista Sujeito 4).

Percebe-se outro traço cultural na preferência de cervejas artesanais a outras opções mais comerciais, para promover um consumo consciente, mais regional e menos massificado.

Mas hoje um dos fatores preponderantes é o que, eu vejo isso mais no consumo como uma forma de rebeldia para ser contra grandes corporações do que um conceito de consumo. É muito delicado, tem questão política, social (Entrevista Sujeito 8).

\subsection{Discussão}

O crescimento do setor microcervejeiro artesanal catarinense evidencia uma orientação empreendedora facilitadora de comportamentos focados na busca e exploração de novas oportunidades (Covin \& Slevin, 1989; Huang \& Wang, 2011; Hult et al., 2004; Zhao et al., 2011), envolvendo aceitação de riscos, proatividade no mercado, agressividade competitiva inovatividade da empresa, que são dimensões da OE (Miller \& Friesen, 1983; Wang, 2008).

A indústria de cerveja é controlada por grandes cervejarias, o que deixa os microcervejeiros artesanais vulneráveis neste mercado competitivo. Esta situação criou uma cultura colaborativa na indústria, o que incentiva às pequenas empresas a trabalharem em conjunto para resolver problemas.

$\mathrm{Na}$ luta pela sobrevivência e o crescimento, os produtores artesanais percebem uma crescente agressividade no mercado, principalmente com as grandes cervejarias, o que estimula a necessidade de cooperação, parcerias logísticas com outros microcervejeiros, surgindo a "coopetição". Dito termo explica a ação de "competir e cooperar ao mesmo tempo" (Nalebuff \& Brandenburger, 1996, p. 14).

Foram evidenciadas as dimensões da CAO: experimentação, propensão ao risco, interação com o ambiente externo, diálogo interno e tomada de decisão participativa (Alegre e Chiva, 2008). A comunicação aberta foi observada, embora que restrita a ambientes de produção e; a tomada de decisão limitada aos gestores. Ao que tudo indica, isto se deve ao tipo de empresa familiar, prevalecente neste setor.

A personalidade empreendedora engloba as decisões, visões e intuições do indivíduo isolado. Esse fato pode indicar uma limitação na $\mathrm{OE}$, que conforme Wang (2008), organizações com maior OE são mais propensas a eliminar estruturas tradicionais autoritárias e hierárquicas que inibem a CAO e a inovação.

$\mathrm{Na}$ interação com o ambiente externo, as parcerias entre microcervejeiros utilizam das redes sociais, eventos como feiras, exposições e festivais. Existe também colaboração com os fornecedores, clientes, parceiros de treinamento e associações de classe, quem promovem a troca para fortalecimento do setor. A literatura destaca o caráter interativo do processo inovativo, sugerindo que este seja favorecido pela presença de relações, alianças e interações com fontes externas de conhecimento (Brown \& Eisenhardt, 1995; Ren et al., 2015).

Observou-se, nos resultados desta pesquisa, a aprendizagem organizacional como antecedente da inovação (Baker \& Sinkula, 1999; JiménezJiménez \& Sanz-Valle, 2011), pois a inovação depende da capacidade das organizações para aprender (Alegre \& Chiva, 2008). Cada produto fabricado pelas cervejarias possui uma complexidade que precisa de muita sensibilidade e conhecimento produtivo.

$\mathrm{O}$ conhecimento permite às organizações conseguir a velocidade e flexibilidade inerentes ao processo inovativo (Brown \& Eisenhardt, 1995; Jiménez-Jiménez \& Sanz-Valle, 2011). Nesse contexto, as organizações assumem o risco de criar produtos novos seguindo a orientação do mercado. Este resultado coincide com os achados de Huang e Wang (2011), as organizações precisam desenvolver novos produtos para satisfazer mercados e clientes.

Em resposta à pergunta de pesquisa, com base nos achados do estudo pode-se confirmar que a OE e a CAO contribuem no desenvolvimento da inovação de produtos e projetos inovadores e do desempenho inovador e organizacional coincidindo com a literatura analisada, que indica que a CAO é um ativo que permite às empresas transformar e explorar os seus recursos para desenvolver inovações de produtos ou processos (Amara, et. al 2008).

Cabe destacar que, os microcervejeiros percebem a necessidade de lucratividade para sobrevivência, razão pela qual controlam custos em

Revista de Negócios, v. 22, n. 3, p. 64-8o, July, 2017. 
nível geral, no entanto, não discriminam os custos relativos a produtos novos, o que poderia fornecer uma visão mais clara do DI, que hoje se centra no monitoramento de produtos novos, pontos de venda e acompanhamento da redução de custos visando aumentar a eficiência.

Também, pode-se constatar que na perspectiva dos entrevistados, as empresas do setor microcervejeiro catarinense com $\mathrm{OE}$ são mais propensas a apresentarem CAO, observando-se também a relação inversa: a CAO melhora as habilidades de gestão. Fernández-Mesa et al. (2012) sugerem que a CAO media a relação entre OE e desempenho inovador e organizacional, portanto a $\mathrm{OE}$ facilita a aprendizagem para melhorar a performance.

Conforme Amara, et al. (2008), para se tornarem inovadoras ou aumentarem o grau de novidade de suas inovações, as pequenas empresas precisam melhorar sua CAO, ou seja, sua capacidade de criar internamente novos conhecimentos, bem como melhorar sua capacidade para identificar, assimilar e explorar o conhecimento do seu ambiente externo.

Outros temas que emergiram da análise das entrevistas e que formam parte do contex to do setor microcervejeiro catarinense foram os principais obstáculos para a inovação do setor, a importância da figura do fundador e a questão cultural local. Este último contribuiu com o renascimento da indústria cervejeira artesanal (Morado, 2009) permitindo que as microcervejarias artesanais priorizem a fabricação de bebidas mais elaboradas e de melhor qualidade, quebrando assim o mainstream (Giorgi \& Conceição Junior, 2016).

\section{Considerações Finais}

Esta pesquisa qualitativa teve como objetivo analisar a relação entre a orientação empreendedora (OE) e a capacidade de aprendizagem organizacional (CAO) no desempenho inovador e organizacional em um conjunto de sete microcervejarias, localizadas em cinco cidades do Estado de SC. Para tanto foram entrevistados oito gestores e membros da equipe de produção de diversas microcervejarias, algumas destas, participantes do Projeto Vale da Cerveja/SC.

Foram evidenciadas as dimensões da OE: aceitação de riscos, proatividade no mercado, agressividade competitiva inovatividade da empresa (Miller \& Friesen, 1983; Wang, 2008) e da CAO: experimentação, propensão ao risco, interação com o ambiente externo, diálogo interno e tomada de decisão participativa (Alegre e Chiva, 2008) na abordagem da inovação por meio da geração de novos produtos e projetos. Observou-se a CAO como antecedente da inovação (Baker \& Sinkula, 1999; Jiménez-Jiménez \& Sanz-Valle, 2011).

Esta pesquisa também pode confirmar que a OE e a CAO contribuem no desenvolvimento da inovação de produtos e projetos inovadores e do desempenho inovador e organizacional. Quanto à relação com o DI, na perspectiva dos entrevistados, ela é centrada ao monitoramento de produtos novos, novos pontos de venda e redução de custos com miras a aumentar a eficiência, diminuindo o desperdiço.

Também, pode-se constatar que na perspectiva dos entrevistados, as empresas do setor microcervejeiro catarinense com $\mathrm{OE}$ são mais propensas a apresentarem CAO, e vice-versa. A OE facilita a aprendizagem para melhorar a performance e a CAO gera mudanças nos modelos organizacionais e de gestão, visando melhorar o DI e DO.

Alguns tópicos novos emergiram da análise das entrevistas e que formam parte do quotidiano do empreendedor microcervejeiro catarinense como os obstáculos para a inovação do setor, a importância do fundador e mentor das organizações e a influência da cultura germânica.

O estudo enfatizou a importância dos fatores facilitadores da aprendizagem organizacional, uma vez que eles contribuem direta ou indiretamente no DI. Além da inovação de produtos, há também a necessidade de criatividade contínua nas áreas de embalagem, comércio eletrônico, preços e disponibilidade dos produtos no varejo.

Ainda, observou-se que a centralização de autoridade na organização familiar, estrutura típica do setor microcervejeiro catarinense limita a comunicação aberta e tomada de decisão participativa, dimensões da CAO. Neste tipo de empresas, a personalidade empreendedora engloba as decisões, visões e intuições em um indivíduo isolado, limitando a $\mathrm{OE}$, o que pode constituir-se em uma limitação para o processo inovativo.

Dentre as limitações identificadas nesta pesquisa estão a impossibilidade de generalização das informações e análises sobre a relação pesquisada. Outro fator limitador foi relacionado

Revista de Negócios, v. 22, n. 3, p. 64-8o, July, 2017. 
ao desempenho inovador, uma vez que quando solicitado aos gestores identificarem as inovações de produtos, estes podem tender a superestimar o grau de novidade ou a singularidade de suas inovações, ou ainda, podem até ter percepções imprecisas sobre os produtos disponíveis nos mercados.

Pode-se supor que esse fator seja ainda maior para as pequenas e médias empresas, que têm menos informações sobre o ambiente competitivo em que operam. Novas pesquisas podem explorar a relação da OE e CAO na facilitação do desempenho inovador em outros setores industriais e realidades socioespaciais.

\section{Agradecimentos}

Os autores agradecem ao Conselho Nacional de Desenvolvimento Científico e Tecnológico (CNPq) pelo apoio recebido para a realização desta pesquisa.

\section{Referências}

Aarts, B., \& Bauer, M. (2002). A construção do corpus: um princípio para a coleta de dados qualitativos. In Pesquisa Qualitativa com Texto, Imagem e Som: Um manual prático. Petrópolis: Editora Vozes.

Aizpurúa, L., Saldaña, P., \& Saldaña, A. (2011). Learning for sharing: an empirical analysis of organizational learning and knowledge sharing. International Entrepreneurship and Management Journal, 7(4), 509-518.

Alegre, J., \& Chiva, R. (2008). Assessing the impact of organizational learning capability on product innovation performance: An empirical test. Technovation, 28(6), 315-326.

Alegre, J., \& Chiva, R. (2013). Linking entrepreneurial orientation and firm performance: The role of organizational learning capability and innovation performance. Journal of Small Business Management, 51(4), 491-507.

Amara, N., Landry, R., Becheikh, N., \& Ouimet, M. (2008). Learning and novelty of innovation in established manufacturing SMEs. Technovation, 28(7), 450-463.
Aragón-Correa, J. A., García-Morales, V. J., \& Cordón-Pozo, E. (2007). Leadership and organizational learning's role on innovation and performance: Lessons from Spain. Industrial Marketing Management, 36(3), 349-359.

Atuahene-Gima, K., \& Ko, A. (2001). An empirical investigation of the effect of market orientation and entrepreneurship orientation alignment on product innovation. Organization Science, 12(1), 54-74.

Atuahene-Gima, K., Slater, S. F., \& Olson, E. M. (2005). The contingent value of responsive and proactive market orientations for new product program performance. Journal of Product Innovation Management, 22(6), 464-482.

Baker, W. E., \& Sinkula, J. M. (1999). The Synergistic Effect of Market Orientation and Learning Orientation on Organizational Performance. Journal of the Academy of Marketing Science, 27(4), 411-427.

Bapuji, H., \& Crossan, M. (2004). From questions to answers: reviewing organizational learning research. Management Learning, 35(4), 397-417.

Bauer, M. W., \& Gaskell, G. (2002). Pesquisa qualitativa com texto, imagem e som. Petrópolis: Vozes.

Brown, S., \& Eisenhardt, K. (1995). Product Development: Past Research, Present Findings and Future Directions. The Academy of Management Review, 20(2), 343-378.

Chen, Y., Wang, Y., Nevo, S., Benitez-Amado, J., $\&$ Kou, G. (2015). IT capabilities and product innovation performance: The roles of corporate entrepreneurship and competitive intensity. Information and Management, 52(6), 643-657. http://doi.org/10.1016/j.im.2015.05.003

Chiva, R., \& Alegre, J. (2009). Organizational learning capability and job satisfaction: An empirical assessment in the ceramic tile industry. British Journal of Management, 20(3), 323-340.

Chiva, R., Alegre, J., \& Lapiedra, R. (2007). Measuring organisational learning capability among the workforce. International Journal of Manpower, 28(3/4), 224-242.

Revista de Negócios, v. 22, n. 3, p. 64-8o, July, 2017. 
http://doi.org/10.1108/01437720710755227

Chiva, R., Ghauri, P., \& Alegre, J. (2014). Organizational Learning, Innovation and Internationalization: A Complex System Model. British Journal of Management, 25(4), 687-705.

Covin, J. G., \& Slevin, D. P. (1989). Strategic management of small firms in hostile and benign environments. Strategic Management Journal, 10(1), 75-87.

Creswell, J. W. (2010). Projeto de pesquisa métodos qualitativo, quantitativo e misto. In Projeto de pesquisa métodos qualitativo, quantitativo e misto. Porto Alegre: Artmed.

Crossan, M. M., \& Berdrow, I. (2003). Organizational learning and strategic renewal. Strategic Management Journal, 24(11), 10871105.

Cunha, T. V. da. (2011). Competitividade e segmentação na indústria cervejeira: uma análise da competitividade das microcervejarias catarinenses.

Eggers, F., \& Kraus, S. (2012). Growing Young SMEs in Hard Economic Times: The Impact of Entrepreneurial and Customer Orientations - A Qualitative Study from Silicon Valley Growing Young SMEs in Hard Economic Times: The Impact of Entrepreneurial and Customer Orientations, 6331(January 2016), 99-111.

Fernández-Mesa, A., Alegre-Vidal, J., \& ChivaGómez, R. (2012). Orientación emprendedora, capacidad de aprendizaje organizativo y desempeño innovador. Journal of Technology Management \& Innovation, 7(2), 157-170.

Ferreira, R. H., Vasconcelos, R. L., Martins, V. M., \& Neves, J. T. de R. (2011). Inovação na fabricação de cervejas especiais na região de Belo Horizonte. Perspectivas Em Ciência Da Informação, 16(4), 171-191.

Flick, U. (2009). Introdução à Pesquisa Qualitativa. (Artmed, Ed.) (3.). Porto Alegre: Artmed.

Forrester, R. H. (2000). Capturing learning and applying knowledge: an investigation of the use of innovation teams in Japanese and American automotive firms. Journal of Business Research, 47(1), 35-45.

Giorgi, V. V. de. (2016). "Cultos em cerveja": discursos sobre a cerveja artesanal no Brasil. Sociedade e Cultura, 18(1).

Giorgi, V. V. de, \& Conceição Junior, J. (2016). A Produção Cervejeira como Patrimônio Intangível. Cultura Histórica \& Patrimônio.

Gumusluoglu, L., \& Ilsev, A. (2009). Transformational leadership, creativity, and organizational innovation. Journal of Business Research, 62(4), 461-473.

Huang, S. K., \& Wang, Y.-L. (2011). Entrepreneurial orientation, learning orientation, and innovation in small and medium enterprises. Procedia - Social and Behavioral Sciences, 24, 563-570.

Hult, G. T. M., Hurley, R. F., \& Knight, G. A. (2004). Innovativeness: Its antecedents and impact on business performance. Industrial Marketing Management, 33(5), 429-438.

Hurley, R. F., \& Hult, G. T. M. (1998). Innovation, market orientation, and organizational learning: an integration and empirical examination. The Journal of Marketing, 42-54.

Ipe, M. (2003). Knowledge sharing in organizations: A conceptual framework. Human Resource Development Review, 2(4), 337-359.

Ireland, R. D., \& Webb, J. W. (2007). Strategic entrepreneurship: Creating competitive advantage through streams of innovation. Business Horizons, 50(1), 49-59.

Isaacs, W. N. (1993). Taking flight: Dialogue, collective thinking, and organizational learning. Organizational Dynamics, 22(2), 24-39.

Jiménez-Jiménez, D., \& Sanz-Valle, R. (2011). Innovation, organizational learning, and performance. Journal of Business Research, 64(4), 408-417.

http://doi.org/10.1016/j.jbusres.2010.09.010

Knudsen, M. P., \& Cokpekin, Ö. (2011). Does organizational creativity really lead to innovation. 
Innovation, Strategy, and Structure, Organizations, Institutions, Regions, DRUID.

Koch, L. (2017). Jaraguá pode se tornar polo cervejeiro. Retrieved March 10, 2017, from http://ocponline.com.br/noticias/jaragua-pode-

virar-polo-cervejeiro

Lumpkin, G., \& Dess, G. (1996). Clarifying the entrepreneurial orientation construct and linking it to performance. Academy of Management Review, 21(1), 135-172.

Lumpkin, G., \& Dess, G. G. (2001). Linking two dimensions of entrepreneurial orientation to firm performance: The moderating role of environment and industry life cycle. Journal of Business Venturing, 16(5), 429-451. http://doi.org/10.1016/S0883-9026(00)00048-3

Marshall, M. N. (1996). Sampling for qualitative research. Family Practice, 13(6), 522-526.

Maykut, P., \& Morehouse, R. (1994). Beginning qualitative research: A philosophic and practical approach. Bristol: Falmer.

Miller, D., \& Friesen, P. H. (1983). Innovation in Conservative and Entrepreneurial Firms: Two Models of Strategic Momentum. Strategic Management Journal, 3, 1-25, 3(1), 1-25.

Morado, R. (2009). Larousse de cerveja. Editora Lafonte.

Moreno, A. M., \& Casillas, J. C. (2008). Entrepreneurial orientation and growth of SMEs: A causal model. Entrepreneurship: Theory and Practice, 32(3), 507-528. http://doi.org/10.1111/j.1540-6520.2008.00238.x

Nalebuff, B. J., \& Brandenburger, A. M. (1996). Co-opetição. Rio de Janeiro: Rocco, 28-35.

Nonaka, I., \& Takeuchi, H. (1995). The knowledge-creating company: How Japanese companies create the dynamics of innovation. Oxford university press.

Rauch, A., Wiklund, J., Lumpkin, G. T., \& Frese, M. (2009). Entrepreneurial orientation and business performance: An assessment of past research and suggestions for the future.
Entrepreneurship: Theory and Practice, 33(3), 761-787. 6520.2009.00308.x

Ren, S., Eisingerich, A. B., \& Tsai, H.-T. (2015). How do marketing, research and development capabilities, and degree of internationalization synergistically affect the innovation performance of small and medium-sized enterprises (SMEs)? A panel data study of Chinese SMEs. International Business Review, 24(4), 642-651.

Scott-Ladd, B., \& Chan, C. C. A. (2004). Emotional intelligence and participation in decision-making: strategies for promoting organizational learning and change. Strategic Change, 13(2), 95-105.

SEBRAE. (2015). Inteligência Setorial: Cervejas Artesanais. Retrieved September 1, 2016, from https://www.sebraeinteligenciasetorial.com.br/pro dutos/relatorios-de-inteligencia/cervejasartesanais/55c4ad3614d0c01d007ffeae\#download

Senge, P. M. (2009). A quinta disciplina: arte e prática da organização que aprende. Best Seller.

Slater, S. F., \& Narver, J. C. (1995). Market orientation and the learning organization. The Journal of Marketing, 63-74.

Trigo, A. (2013). Mechanisms of learning and innovation performance: The relevance of knowledge sharing and creativity for nontechnological innovation. International J. of Innovation and Technology Management, 10(6).

Wang, C. L. (2008). Entrepreneurial orientation, learning orientation, and firm performance. Entrepreneurship: Theory and Practice, 32(4), 635-657.

Wiklund, J., \& Shepherd, D. (2005). Entrepreneurial orientation and small business performance: A configurational approach. Journal of Business Venturing, 20(1), 71-91.

Yeung, A. C. L., Lai, K., \& Yee, R. W. Y. (2007). Organizational learning, innovativeness, and organizational performance: a qualitative investigation. International Journal of Production Research, 45(11), 2459-2477. 
Zhao, Y., Li, Y., Lee, S., \& Chen, L. (2011).

Entrepreneurial Orientation, Organizational

Learning, and Performance: Evidence From China.

Entrepreneurship: Theory and Practice, 35(2), 293-317.

Revista de Negócios, v. 22, n. 3, p. 64-8o, July, 2017. 